\title{
Investigation into the attitudes of general practitioners in Staffordshire to medical audit
}

\author{
Ruth Chambers, Susan Bowyer, Ian Campbell
}

\begin{abstract}
Objectives - To investigate the attitudes of general practitioners to medical audit, and any associations between their attitudes and their personal characteristics.

Design - Postal questionnaire survey. Setting - Staffordshire, United Kingdom.

Subjects - 870 Staffordshire general practitioners.

Main measures - Agreement or disagreement and associations between the attitudes to 16 statements about audit and the doctors' personal or practice characteristics - namely, sex, number of years since qualification, practice list size, number of partners, and the practices' experience of audit.
\end{abstract}

Results - 601 Staffordshire general practitioners $(69 \%)$ responded. There was most agreement with the statements that audit is time consuming $(86 \%)$, that ongoing training and education is needed $(71 \%)$, that there is a compulsion applied on doctors to audit $(68 \%)$, and that extra resources for audit should be provided by the medical audit advisory group (65\%). There was considerable disagreement (53\% of general practitioners) with the statement that "government policy to expect general practitioners to do audit will enhance the population's health." The median response by the 601 general practitioners was four positive responses out of 14 statements about audit (two of the 16 statements could not be graded positive or negative to audit). Women doctors generally had more positive attitudes towards audit, and so had those working with smaller mean list sizes, those in larger partnerships, and those in practices that had carried out audit for a longer time.

Conclusions - There was a generally negative attitude to medical audit, but it was encouraging that those doctors with the most experience of audit obtained the most job satisfaction from it.

Implications - More effort is needed to convince general practitioners of the value of audit. Without this, attempts to involve other members of the primary care team in multidisciplinary clinical audit are unlikely to be effective. Successful audits that are shown to be cost effective as well as leading to improvements in patient care should be publicised and replicated. A higher proportion of resources should be devoted to audit.

(Quality in Health Care 1996;5:13-19)

Keywords: audit, attitudes, questionnaire

\section{Introduction}

Ideally, medical audit (box) should be part of routine clinical practice and lead to an improvement in the quality of care. ${ }^{12}$ However, not all general practitioners have accepted the concept of medical audit and put it into practice, ${ }^{34}$ and surveys of audits actually carried out in primary care have shown a wide range in the quality and quantity of audit performed by general practitioners. $^{34}$

\section{System for audit in general practice in England and Wales}

- Medical audit advisory groups were set up in England and Wales from April 1991 to promote audit in general practice

- Each family health service area has at least one audit group. There were 104 groups in July 1994

- The audit groups are composed of general practitioner representatives plus other people, such as a representative from the local family health service area, a hospital consultant, a practice nurse, or a practice manager

- Each audit group receives funds from the family health service area and employs one or more facilitators and administrative staff

- The activities undertaken by audit groups include the provision of training about audit, circulation of newsletters, promotion of audit by individual practice teams, and the organisation of audit projects in which large numbers of practices are encouraged to participate

Potential barriers to audit in primary care have been described, ${ }^{56}$ and include uncertainty about its nature or relevance, concern about failures or mistakes being disclosed through the audit process, resistance to change, limitation of resources, competing pressures of work, and problems of implementation due to poor organisation and communication within the practice.

It seems clear that the active involvement of interested and motivated doctors is crucial to the success of audit, ${ }^{6}$ and there are examples 
in which audit has been successfully carried out by small groups of motivated practitioners. ${ }^{5} 8$ There are also some indications that as general practitioners become more familiar with audit and gain experience, their interest in audit increases and their fear diminishes. ${ }^{9} \mathrm{~A}$ facilitatory approach by one medical audit advisory group has been thought to have contributed to a change in attitude in general practitioners, and encouraged more openness about their work and problems. ${ }^{10}$

Understanding the attitudes of general practitioners to audit would help those facilitating audit to encourage those not yet fully involved. In this paper we report the results of a study that set out to investigate the attitudes of general practitioners in Staffordshire to medical audit. We considered general attitudes to audit as well as specific areas of discontent that might be open to change. We also aimed to discover whether there are any particular personal or practice characteristics associated with general practitioners having a more positive attitude to medical audit. Possible methods to increase general practitioners' enthusiasm for medical audit are considered.

\section{Methods}

A questionnaire (appendix) was devised to assess the opinions of general practitioners about medical audit. It comprised 16 statements about medical audit phrased in an equal number of positive and negative ways. The questions were framed to reflect the expressed views and words of the participants in two previous focus group discussions involving 14 general practitioners. Nine of these 14 doctors attending had shown previous interest in learning about medical audit. The questionnaire was tested in a pilot study and was amended as necessary.

In November 1992 the questionnaire was sent to the 870 general practitioners with patients in Staffordshire. The intention was to include all general practitioners with whom the Staffordshire Medical Audit Advisory Group had contact. These comprised the 498 general practitioners who were based in Staffordshire together with the 372 general practitioners located at the borders of the county who had some patients in Staffordshire but whose advisory group was one of the six adjacent to Staffordshire.

Respondents were asked to indicate, on a five point Likert scale, their score for agreement with each of the 16 statements, in which 1 denoted "strongly agree" and 5 "strongly disagree". For analysis, each statement was judged by the authors either to be in favour of audit, or to be against audit (or in two cases to be neutral). This judgement is shown on the copy of the questionnaire in the appendix as +ve (indicating in favour), -ve (indicating against), or 0 (neutral); these codes were not on the distributed questionnaire. For each respondent, a positivity score was calculated as the number of positive statements with which the doctor agreed, plus the number of negative statements with which the doctor disagreed, giving a score in the range of 0 to 14 .

The questionnaires were returned in freepost envelopes. A code number was attached to one corner of the questionnaire to allow the general practitioner's personal and practice characteristics to be obtained from the medical audit advisory group database, and to aid follow up of non-respondents. Nonrespondents were reminded twice.

Non-respondents (and those doctors who had replied anonymously) were sent a short enquiry sheet inviting them to mark their reasons for non-response. Questionnaires associated with replies that indicated that the subject had previously responded anonymously were discarded.

Information was obtained from the appropriate advisory group on the subjects' age, sex, number of years qualified, and number of practice partners. Additional data about those general practitioner respondents based in the Staffordshire Medical Audit Advisory Group area were obtained from the practice list size, the Jarman index of deprivation for the practice area, the time for which medical audit had been carried out, and the quality of the audit in the practices of the individual respondents. The duration of audit was categorised as $(a)$ had not been started, (b) had only just started, (c) had been carried out for less than two years, or $(d)$ had been carried out for more than two years. The quality of audit was judged from the Oxford classification system ${ }^{3}$ of the practices' best audit projects, as described elsewhere. ${ }^{11}$ Information was not available on the number of years qualified in six cases, the number of partners in five cases, the list size in three cases, the duration of audit in 68 cases, and the quality of audit in 47 cases.

\section{ANALYSIS AND STATISTICS}

A Minitab software package was used to process the responses to the questionnaire. Associations between the responses to the 16 statements and the seven general practitioner characteristics were tested by calculation of Spearman's rank correlation coefficient, except in the case of sex, for which a MannWhitney $U$ test was used. ${ }^{12}$ The calculations for both tests included allowances for ties. Some of the categories have been combined for clarity of presentation - for example, in table 2 responses of "strongly agree" have been combined with responses of "agree" but, all statistical tests were done on the original data. All $\mathbf{P}$ values calculated were twotailed.

\section{Results}

There were 601 replies from the 870 Staffordshire general practitioners (response rate $69 \%$ ). Thirty four were anonymous. Of those not replying anonymously $20 \%$ were women, and the mean(SD) age was $44 \cdot 0(9 \cdot 4)$ years, which was younger than the age of the non-responders $(48 \cdot 6(9 \cdot 1), \mathrm{P}<0.0001, t$ test $)$. Of these 567 identifiable respondents $63 \%$ were based in Staffordshire, and the rest 
practised partly in Staffordshire but were based in the six adjacent medical audit advisory group areas. Table 1 shows the distribution of the recorded duration and quality of medical audit in the practices of the 335 doctors working in the Staffordshire advisory group area.

Table 2 shows the overall levels of agreement for the 16 statements of the questionnaire in descending order of agreement. Most doctors thought that audit is time consuming, two thirds agreed that ongoing training and education are needed, that there

Table 1 Details of the experience of audit of responding general practitioners working in the Staffordshire medical audit advisory group area

\begin{tabular}{lc}
\hline & $\begin{array}{c}\text { Respondents } \\
n(\%)\end{array}$ \\
\hline Duration of audit experience: & \\
Not started & $42(13)$ \\
On first project & $31(9)$ \\
Carried out for $\leqslant 2$ y & $99(30)$ \\
Carried out for $>2$ y & $95(28)$ \\
Unknown & $68(20)$ \\
Total & $335(100)$ \\
Quality of best audit by Oxford classification: & \\
No audit & $32(10)$ \\
Planning & $15(4)$ \\
Potential & $46(14)$ \\
Partial & $76(23)$ \\
Full & $119(36)$ \\
Unknown & $47(14)$ \\
Total & $335(100)$ \\
\hline
\end{tabular}

Table 2 Percentage agreement of general practitioners for the 16 statements about medical audit, in descending order of agreement $(n=601)$

\begin{tabular}{lcccc}
\hline Statement (shortened) & $\begin{array}{c}\text { Strongly } \\
\text { agree or } \\
\text { agree }\end{array}$ & $\begin{array}{c}\text { Neither } \\
\text { agree nor } \\
\text { disagree }\end{array}$ & $\begin{array}{c}\text { Disagree } \\
\text { or strongly } \\
\text { disagree }\end{array}$ & $\begin{array}{c}\text { Don't } \\
\text { know }\end{array}$ \\
\hline
\end{tabular}

Audit is time consuming

Ongoing training or education needed

Compulsion attached to audit

MAAG should provide resources for audit

Audit has been imposed from the outside

Audit may favour one area over another

I can learn from mistakes without audit

An essential aid to future planning

Audit highlights reality

The MAAG is a useful resource

Practice staff feel threatened by audit

Audit increases my job satisfaction

Audit increases my job satisfaction

The MAAG may pass on audit details without

The MAAG

Audit will enhance population's health

I prefer audit likely to affect income rather than clinical performance

MAAG = medical audit advisory group.

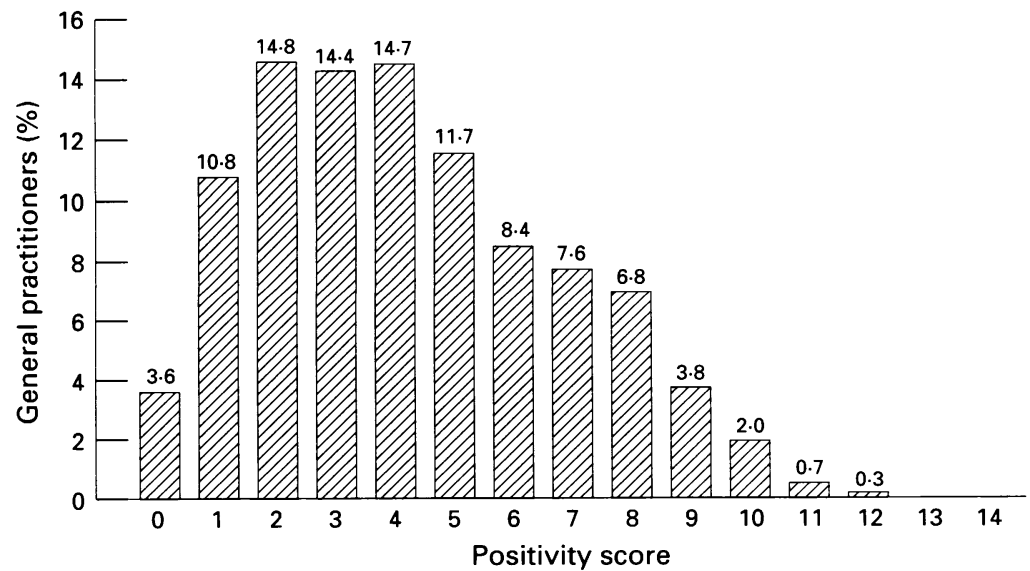

Positivity scores for the 601 general practitioners - that is, the number of statements in favour of audit with which the doctor agreed plus the number of negative statements with which the doctor disagreed. (The maximum possible score was 14.) is an element of compulsion involved in audit, and that the advisory group should provide resources for audit projects. Over half of the general practitioners disagreed with the statement that "government policy to expect general practitioners to do audit will enhance the populations's health," and there was little support for doing audit likely to affect income rather than clinical performance. The positivity score for the respondents ranged from 0 to 12 out of a possible 14 , with a median of 4 (fig).

There were 151 replies ( $56 \%$ response) to the short enquiry that was sent to nonrespondents (discounting those who indicated they had previously replied anonymously). The main reasons given by non-respondents for not replying to the main attitude questionnaire were: insufficient time (60\%), never respond to questionnaires $(19 \%)$, questionnaire lost or forgotten ( $11 \%$ ), and disinterest in medical audit (7\%).

CORRELATIONS BETWEEN AGREEMENT OF GENERAL PRACTITIONERS WITH MEDICAL AUDIT STATEMENTS AND THEIR PERSONAL AND PRACTICE CHARACTERISTICS

Table 3 shows the Spearman correlation coefficients calculated between the levels of agreement with the 16 medical audit statements and the details of the general practitioners' practices, experience of audit, sex, and number of years since qualification. There were 29 correlations at the $5 \%$ level of significance, whereas six could have been expected to occur by chance.

A positive correlation denotes an association between agreement with the statement and a high value of the characteristic, and a negative correlation indicates an association between agreement with the statement and a low value of the characteristic. (Women were coded 1 and men were coded 2 for the calculations).

Sex differences $(n=567)$

Women general practitioners were significantly more likely than the men to agree with six out of the seven positive statements in the questionnaire. The men were significantly more likely than the women to agree with one of the seven negative and one of the neutral statements. The women were significantly more likely than the men to report that audit increases their job satisfaction ( $45 \%$ women versus $36 \%$ men, $P<0.03$ ), perceive ongoing training and education as necessary $(85 \%$ women versus $69 \%$ men, $P<0.03$ ), see the advisory group as a useful resource $(59 \%$ women versus $40 \%$ men, $P<0.001$ ), think that audit almost always leads to a change for the better (33\% women versus $26 \%$ men, $\mathrm{P}<0.03)$, agree that audit highlights reality ( $57 \%$ women versus $45 \%$ men, $P<0.02$ ), and agree that audit is an essential aid to future planning $(68 \%$ women versus $46 \%$ men, $\mathrm{P}<0.001)$. The men were significantly more likely to agree with the statement that there is compulsion attached to audit $(72 \%$ men versus $57 \%$ women, $\mathrm{P}<0.005)$ and were more likely to prefer to carry out audits about income rather than clinical performance 
Table 3 Correlations between agreement with medical audit statements and personal or practice characteristics of the Staffordshire general practitioners

\begin{tabular}{|c|c|c|c|c|c|c|c|}
\hline \multirow[t]{2}{*}{ Statement (shortened) } & \multirow{2}{*}{$\begin{array}{c}\text { Mann- } \\
\text { Whitney } z \\
\text { Sex } \\
n=567\end{array}$} & \multicolumn{6}{|c|}{ Spearman's correlation coefficients } \\
\hline & & $\begin{array}{c}\text { Years } \\
\text { qualified } \\
n=561\end{array}$ & $\begin{array}{c}\text { List } \\
\text { size } \\
n=333\end{array}$ & $\begin{array}{c}\text { Number of } \\
\text { partners } \\
n=565\end{array}$ & $\begin{array}{c}\text { farman } \\
\text { index } \\
n=310\end{array}$ & $\begin{array}{c}\text { Time audit } \\
\text { done } \\
n=267\end{array}$ & $\begin{array}{l}\text { Oxford } \\
\text { criteria } \\
n=288\end{array}$ \\
\hline Audit increases my job satisfaction & $2 \cdot 1^{\star}$ & -0.04 & $-0 \cdot 14^{\star}$ & -0.06 & $0 \cdot 10$ & $0 \cdot 17^{\star \star}$ & $0 \cdot 12$ \\
\hline Practice staff feel threatened by audit & 0.28 & 0.04 & -0.01 & $-0 \cdot 14^{\star \star}$ & -0.01 & $-0 \cdot 14^{\star}$ & $-0 \cdot 11$ \\
\hline Audit has been imposed from the outside & -0.66 & 0.03 & 0.08 & $-0 \cdot 11^{\star}$ & $-0 \cdot 11$ & $-0 \cdot 14^{\star}$ & $-0 \cdot 15^{\star}$ \\
\hline $\begin{array}{l}\text { The MAAG may pass on audit details } \\
\text { without consent }\end{array}$ & $-0 \cdot 25$ & $0 \cdot 12^{\star}$ & 0.01 & $-0 \cdot 16^{\star \star}$ & $-0 \cdot 11$ & $-0 \cdot 20^{\star \star}$ & $-0 \cdot 20^{\star \star}$ \\
\hline Audit is time consuming & -0.34 & -0.03 & 0.01 & -0.08 & $-0 \cdot 12^{\star}$ & -0.09 & $-0 \cdot 11$ \\
\hline Ongoing training or education needed & $2 \cdot 2^{\star}$ & -0.01 & -0.03 & -0.07 & -0.02 & -0.01 & 0.01 \\
\hline The MAAG is a useful resource & $3 \cdot 7^{\star \star}$ & 0.04 & $-0 \cdot 13^{\star}$ & -0.06 & 0.01 & -0.02 & -0.01 \\
\hline Audit will enhance populations's health & 1.05 & 0.02 & $-0 \cdot 13^{\star}$ & -0.09 & 0.08 & 0.03 & 0.06 \\
\hline Compulsion attached to audit & $-2 \cdot 8^{\star \star}$ & -0.02 & $0 \cdot 16^{\star \star}$ & -0.03 & 0.06 & -0.04 & -0.09 \\
\hline Almost always leads to improvement & $2 \cdot 2^{\star}$ & 0.05 & -0.09 & $-0 \cdot 10^{\star}$ & 0.04 & 0.01 & 0.01 \\
\hline MAAG should provide resources & -0.37 & 0.03 & 0.04 & $-0 \cdot 10^{\star}$ & 0.04 & -0.06 & -0.02 \\
\hline Audit highlights reality & $2 \cdot 3^{\star}$ & -0.04 & -0.03 & -0.01 & 0.05 & -0.01 & -0.01 \\
\hline Audit may favour one area over another & -0.57 & -0.05 & $0 \cdot 13$ & 0.01 & 0.02 & -0.04 & -0.01 \\
\hline $\begin{array}{l}\text { I prefer audit likely to affect income rather } \\
\text { than clinical performance }\end{array}$ & $-2 \cdot 1^{\star}$ & $-0 \cdot 12^{\star \star}$ & 0.03 & $-0 \cdot 15^{\star \star}$ & -0.04 & $-0 \cdot 04$ & 0.03 \\
\hline I can learn from mistakes without audit & -0.42 & 0.02 & 0.01 & -0.02 & -0.06 & -0.07 & -0.07 \\
\hline An essential aid to future planning & $3 \cdot 4^{\star \star}$ & -0.01 & -0.03 & $-0 \cdot 01$ & $0 \cdot 18^{\star \star}$ & $-0 \cdot 01$ & 0.03 \\
\hline
\end{tabular}

${ }^{\star} P<0.05 ;{ }^{\star} \mathbf{P}<0.01$. MAAG $=$ medical audit advisory group.

(disagreement by $52 \%$ men versus $67 \%$ women, $\mathrm{P}<0.04)$.

Years since qualification $(n=561)$

Doctors with more years since qualification were more likely to think that audit details given to the advisory groups might be passed on to others without their consent $(P<0.01)$, and younger doctors were more likely to prefer to do audit likely to affect income rather than clinical performance $(\mathrm{P}<0.005)$.

Practice list size $(n=333)$

Doctors with smaller practice lists were more likely to agree that audit increases job satisfaction $(P<0.05)$, that the advisory group is a useful resource $(P<0.05)$, and that audit enhances the populations's health $(P<0.05)$. Doctors in practices with larger lists were more likely to think that there is compulsion attached to audit $(P<0.01)$ and that audit may favour one area over another $(P<0.05)$.

Number of partners in practice $(n=565)$

General practitioners in smaller partnerships were more likely to agree that practice staff may feel threatened by audit $(P<0.01)$, that audit has been imposed $(P<0.05)$, that the advisory group may pass on confidential information $(P<0.01)$, that audit almost always leads to improvement $(P<0.05)$, that the advisory group should provide resources for audit projects $(P<0.05)$, and that they preferred to carry out audit likely to affect income rather than clinical performance $(P<0.01)$.

Farman index of deprivation $(n=310)$

Those respondents from practices in more deprived areas were more likely to agree that audit is time consuming $(P<0.05)$ and were less likely to perceive audit as an essential aid to future planning $(P<0.01)$.

Experience of audit $(n=288)$

Doctors from practices that had carried out audit for longer were more likely to agree that audit increased job satisfaction $(P=0.005)$ and to disagree that audit has been imposed from the outside $(P=0.02)$, that the advisory group may pass on confidential information $(P=0.005)$, and that practice staff may feel threatened by audit $(P=0.03)$.

General practitioner respondents whose practices had done better quality audits as judged by higher Oxford criteria ${ }^{5}$ were more likely to disagree that the advisory group may pass on confidential information $(P<0.05)$ and that compulsion was attached to audit $(\mathrm{P}<0.05)$.

\section{Discussion}

The main finding of the survey was a prevailing negative attitude towards medical audit with only $15 \%$ of the general practitioners who responded agreeing that "Government policy to expect general practitioners to do audit will enhance the population's health," and only $35 \%$ thinking that audit increased their job satisfaction. The median number of positive responses was only four out of the 14 statements about audit. It may well be that the true picture is even worse as the one third who did not return the questionnaire might hold even more negative views. Whether these attitudes of the general practitioners working in Staffordshire are representative of opinion in the United Kingdom is difficult to predict, but the similar results from 389 general practitioners in Nottinghamshire replying to the same questionnaire suggest that it is. ${ }^{13}$ Furthermore, Staffordshire is geographically central to the main population areas of the United Kingdom, and it contains a similar mixture of rural and urban areas as the United Kingdom as a whole. Although the general practitioners were surveyed in 1992-3, we think that little has changed since then, except perhaps for an increasing theoretical emphasis on clinical rather than medical audit. We therefore think that the conclusions from this survey remain valid.

The negative attitudes found in this survey are in line with findings in other European countries where a straw poll ${ }^{14}$ of key people in 
17 countries found that general practitioners' attitudes to quality assurance varied from moderately positive to definitely negative; only in Sweden and the Netherlands did general practitioners seem to have accepted the need for quality assurance. In the Netherlands the development of comprehensive sets of national standards for the clinical management of more than 30 conditions has included the participation of "ordinary" general practitioners; this involvement of local doctors in national policy making may be one of the reasons why Dutch general practitioners seem to have positive attitudes to audit and quality.

RESOURCES AND AUDIT

Other main opinions to emerge from the questionnaire were that audit is time consuming, that there should be ongoing training, and that extra resources are needed for audit. Doctors with smaller lists regarded various aspects of audit more favourably than those with larger lists. Lack of time to do audit is a recognised barrier to its adoption. ${ }^{15}$ It may be that doctors with proportionately fewer patients have more time for audit and are hence more enthusiastic about it. Similarly, doctors practising in the more deprived areas (whose patients are likely to consult more often) were more likely to find audit time consuming.

Doctors in smaller partnerships were generally more likely to make negative responses to the statements. This might be because there is more chance of having an audit enthusiast in a larger group, and the presence of good leadership has been found to be important for audit to be carried through to a successful conclusion. ${ }^{1}$ There may also be more flexibility about delegation of audit work to ancillary staff in larger practices, so that audit would be less burdensome for those general practitioners. These associations indicate that it may be worthwhile for audit resources to be targeted more towards the smaller and single handed practices.

\section{COMPULSION AND AUDIT}

Some degree of compulsion was perceived by more than two thirds of respondents although at present there are no penalties for not auditing. Unless doctors are convinced that audit is useful, compulsion will only serve to encourage defensive audits ${ }^{16}$ which will be of limited value. General practitioners are aware of this, and more than four fifths think that there is a "danger of audit for audit's sake."13

SEX AND AUDIT

Although the number of women general practitioners is increasing, there has been little research carried out to investigate sex differences in attitudes, skills, interests, or styles of working. What is known is that male general practitioners have significantly higher levels of anxiety and depression and more job dissatisfaction than women colleagues. ${ }^{17}$ In this survey, women general practitioners showed a generally more positive attitude towards medical audit. Women general practitioners are still underrepresented in developmental professional roles such as teaching or training, ${ }^{18}$ and a need for action has been recognised ${ }^{19}$ to encourage women to take on more managerial responsibility across the whole National Health Service. The potential for women general practitioners to positively influence the adoption of improvements in primary care such as through medical audit, may not yet have been fully realised.

NUMBER OF YEARS QUALIFIED AND AUDIT The more experienced doctors were more suspicious of the medical audit advisory group, possibly because it is a relatively new organisation, and older doctors might be less willing to accept change. Younger doctors were more likely than older ones to prefer doing audit that might increase their income possibly because they are at a stage in life when their financial outgoings are highest.

\section{ADVISORY GROUPS AND GENERAL}

PRACTITIONERS

Much was made of the separate identities of advisory groups and family health services authorities when they were first set up (box) an arrangement designed to give general practitioners trust in the confidential status of information handled by advisory groups. This intention sems to have succeeded in that only one fifth of respondents thought that the advisory groups might pass on information without the general practitioners' consent. Although relatively new, the advisory groups seem to have become accepted quickly and only a fifth of doctors disagreed with the statement that they are useful. However, it would be unwise to extrapolate nationally from the advisory groups surveyed here as they operate in diverse ways. ${ }^{9}$

\section{ENCOURAGING POSITIVE ATTITUDES}

This questionnaire survey found that many doctors remain unconvinced of the value of audit, in contrast with the enthusiasts who think that good audit will bring about large improvements in patient care. Consequently, priority must be given at national, regional, and local levels to convince doctors in primary care of the benefits of audit. Most work will need to be done locally to gain general practitioners' commitment to and increased participation in audit. Compulsion without education will tend to be counter productive; doctors will be more willing to carry out audit if they perceive it to be useful. Examples of good and successful audits carried out by peers should be well publicised in newsletters and local professional meetings.

It was reassuring to find that general practitioners who had been doing audit for longer were more likely to report that it increased their job satisfaction, and less likely to report that it is perceived as a threat. These associations need cautious interpretation as they may not be directly causal; it is possible that the group of doctors who are most interested in audit were both the first to start to undertake it and also the ones to derive the most satisfaction from it 
and feel most comfortable with it - but at least there is no evidence that increased experience of audit has lead to disillusionment.

More could be done to promote good audit. Health authorities and family health service authorities could inform practices about their performance in relation to that of other practices, with anonymous comparative data on such issues as prescribing, practice staffing, hospital admission rates, the proportion of inadequate smears taken in the practice, and the reporting of infectious diseases. Any exceptional results from a practice would provide a spur for a future internal audit project by that practice. The medical audit advisory groups are well placed to organise county or district wide audits to feed useful information to family health service authorities and health authorities, and any changes that benefit doctors or patients should be well advertised. The vogue for developing locally agreed guidelines on the management of clinical care should provide a ready vehicle for large scale audits.
However much general practitioners come to realise the importance and benefits of audit, they will not carry it out if the resources to do so are not available. This will require action on a national and regional scale to ensure that resources are sufficient for primary care teams to have staff who are funded and trained and who have time dedicated to audit. The advisory groups should have enough manpower to be able to process audits for practices if they require help with analyses and interpretation. Although larger practices may contain an audit enthusiast who takes responsibility for audit, smaller and single practices are less likely to contain such a person, and are more likely to need outside assistance.

Finally, the shift in emphasis to clinical or multidisciplinary audit should encourage a more positive attitude to audit with increased involvement of the team members of a practice, and better communication between different staff and professionals.

We thank the general practitioners who participated in the survey. The study was funded by the Department of Health.

\section{Appendix}

\section{General practitioners' attitudes to medical audit}

The following list of statements concern your feelings towards medical audit.

Please could you indicate how much you agree or disagree with the statements by circling the number which most closely reflects how you feel:

$1=$ Strongly agree

$2=$ Agree

$3=$ Neither agree nor disagree

$4=$ Disagree

$5=$ Strongly disagree

$6=$ Don't know

Try not to ponder on the statements for too long, as your first response will usually be the most accurate.

Audit increases my job satisfaction (+ve)

At present practice staff feel threatened by the idea of audit $(-v e)$

Audit has been imposed from the outside rather than being professionally led (-ve)

Audit details given to the MAAG may be passed on to others without your consent (-ve)

Audit is time consuming for GPs (-ve)

There is a need for ongoing training and education if practices are to undertake audit (+ve)

The MAAG is a useful resource (+ve)

Government policy to expect GPs to do audit will enhance the population's health (+ve)

There is an element of compulsion attached to audit (-ve)

Audit almost always leads to a change for the better (+ve)

The MAAG should provide resources for audit projects (0)

Audit highlights reality (+ve)

Audit carries a danger of favouring one area against another (-ve)

I prefer to do audit likely to affect income rather than clinical performance (0)

I can learn from my own mistakes without audit (-ve)

Audit is an essential aid to future planning (+ve)

Agreement with statement

MAAG = Medical audit advisory group; (+ve) = positive; $(-$ ve $)=$ negative $;(0)=$ neutral. 
1 Department of Health. Medical audit in the family practitioner services. London: DOH, 1990. (Health practitioner services. Lon
circular HC(FP) $(90) 8)$.

2 Department of Health. Clinical audit - meeting and improving standards in healthcare. London: $\mathrm{DOH}, 1993$.

3 Derry J, Lawrence M, Griew K, Anderson J. Humphreys J, Pandher KS. Auditing audits: the method of Oxfordshire Medical Audit Advisory Group. BMF 1991;303:1247-9.

4 Webb SJ, Dowell AC, Heywood P. Survey of general practice audit in Leeds. BMF 1991;302:390-2.

5 Humphrey C, Hughes J. Audit and development in primary care. Chapter 1: audit as innovation. London: King's Fund Centre, 1992 .

6 Kerrison S, Packwood T, Buxton M. Medical audit: taking stock. Chapter II: Providing medical audit. London: King's Fund Centre, 1993. (Medical Audit Series Number 6.)

7 North of England study of standards and performance in general practice. Medical audit in general practice. I: Effects on doctors' clinical behaviour for common childhood conditions. II: effects on health of patients with common childhood conditions. BMF 1992;304 1480-8.

8 Atkinson C, Hayden J. Managing change in primary care. BMF 1992;304:1488-90

Humphrey C, Berrow D. Developing role of medical audit advisory groups. Quality in Health Care 1993;2:232-8.

10 Johnson $\mathrm{R}$. Where have all the pennies gone? The work of Manchester medical audit advisory group. BMF 1994; 309:98-102.
11 Chambers R. Bowyer S, Campbell I. Audit activity and the quality of completed audit projects in primary care
in Staffordshire. Quality in Health Care 1995;4: in Staffor

12 Altman DG. Practical statistics for medical research. London: Chapman and Hall, 1991.

3 Chambers R, Bowyer S, Campbell I. An evaluation of the quality of medical audit in primary care. Keele: Centre for Primary Health Care, University of Keele, 1993. (Report for the Department of Health.)

14 WONCA European Working Party on Quality in Family Practice. Quality assurance in general practice: the state of the art in Europe. Chapter 5. Netherlands: Dutch College of General Practitioners, 1993.

15 Spencer J. Audit in general practice: where do we go from here? Quality in Health Care 1993;2:183-8.

16 Berwick DM. Heal thyself or heal thy system: can doctors help to improve medical care? Quality in Health Care help to improve medic

17 Sutherland VJ, Cooper CL. Identifying distress among general practitioners: predictors of psychological illhealth and job dissatisfaction. Soc Sci Med 1993;37: 575-81.

18 Johnson N, Hasler J, Mant D, Randall T, Jones L, Yudkin $P$. General practice careers: changing experience of men and women vocational trainees between 1974 and 1989. Br ₹ Gen Pract 1993;43:141-5.

19 NHS Management Executive. Women in the NHS - an implementation guide to Opportunity 2000. London: NHS, 1992. 